Froese R., Demirel N., Sampang A. An overall indicator for the good environmental status of marine waters based commercially exploited species. Marine Policy, 2014, http://dx.doi.org/10.1016/j.marpol.2014.07.012

\title{
An overall indicator for the good environmental status of marine waters based on commercially exploited species
}

\author{
Rainer Froese, GEOMAR, Düsternbrooker Weg 20, Kiel, Germany, rfroese@geomar.de \\ Nazli Demirel, Institute of Marine Sciences and Management, Istanbul University, \\ 34134, Istanbul, Turkey
}

Arlene Sampang, FIN, IRRI Khush Hall, College, 4031, Laguna, Philippines

\begin{abstract}
An indicator is presented to assess and monitor the good environmental status of national marine waters based on the status of commercially exploited marine fishes and invertebrates, including fully-assessed as well as data-limited stocks. The overall-indicator consists of one number per year. It summarizes the following sub-indicators: the stock size relative to the size that can produce the maximum sustainable fishing yield; the mortality caused by fishing relative to the natural rate of mortality; the mean length in the catch relative to the length where $90 \%$ of the females reach sexual maturity; and the abundance in national waters relative to mean abundance in the time series. For the example of German marine waters, the overall-indicator shows that only 3 of 19 stocks (Baltic Sea dab, North Sea plaice and North Sea sprat) were above the limit reference point for the overall indicator in 2011. North Sea herring was close to reaching the threshold, but most other stocks were still far below. Apparently fishing mortality was too high to allow recovery of more stocks to levels capable of producing the maximum sustainable yield. The chosen indicators and reference points may prove useful to other scientists tasked with assessing the environmental status of their national waters.
\end{abstract}

Keywords

ecosystem indicators; fisheries; data-limited stock assessment; good environmental status; MSFD; German national marine waters 


\section{Introduction}

Conservation of biological diversity has been recognized as a key responsibility of states to preserve or rebuild healthy ecosystems for the wellbeing of current and future generations (CBD 1992). A central theme in this context is the application of the precautionary principle in the exploitation of living marine resources and the preservation of the marine environment (UNFSA 1995). Towards this goal, states have developed indicators to assess and monitor the status of biological diversity within their jurisdiction. The overarching legal framework for suitable indicators and reference points for commercially exploited marine stocks is provided by the United Nations Convention on the Law of the Sea (UNCLOS 1982) and the Agreement for the implementation of the provisions of the United Nations Convention on the Law of the Sea (UNFSA 1995). From a European perspective there are in addition the Marine Strategy Framework Directive of the European Union (MSFD 2008; COM 2010) and the 2013 reform of the European Common Fisheries Policy (CFP 2013).

There have been several attempts to provide indicators for the assessment of the environmental status of European Seas based on the status of commercially exploited species (ICES 2012, Probst et al. 2013), albeit with reference points that had no base in fisheries science or in the legal instruments cited above, and which led to unrealistic positive results. Thus, the purpose of this study is to present indicators and reference points for the status of commercial stocks in national marine waters based on the concept of maximum sustainable yield and on the existing legal framework (UNCLOS 1982, UNFSA 1995, MSFD 2008, CFP 2013). These indicators are combined into one annual overall indicator and are applied to exploited marine fishes and invertebrates in the territorial waters and the exclusive economic zone (EEZ). Germany was chosen as a test case for the suitability and for the potential results of the proposed indicators.

\section{Materials and methods}

A detailed presentation of the data, the methods, and the application of the methods to the different stocks was beyond the amount of text, tables and figures acceptable for publication in scientific journals. Such detailed presentation is instead made available as online material (Froese and Sampang 2013, 95 p.).

\subsection{Selection of stocks}

Over 200 stocks of commercially exploited marine fishes and invertebrates occur in the Northeast Atlantic and about 100 of these may occur in German marine waters. However, no 
stock is endemic to German marine waters and many species occur there only as strays (rare visitors) and are not commercially exploited there. For example, Saithe (Pollachius virens) is fished by German fishers in the central and northern North Sea, but it is only infrequently found in the southern North Sea. Similarly, the cod (Gadus morhua) stock of the eastern Baltic is important to German fisheries but does not occur in German marine waters. For the purpose of this study only species and stocks that occur regularly in German marine waters and for which suitable data were available were used. The 19 stocks that fulfilled these requirements are listed in Table 1.

Table 1. English and scientific names of species, stock delineation and ICES identification code of stocks evaluated in this report. Stocks with full assessments (time series data on SSB and F) are marked with an asterisk (*) in the last column

\begin{tabular}{|c|c|c|c|}
\hline English name & Scientific name & Stock & ICES ID \\
\hline \multirow[t]{2}{*}{ Cod } & Gadus morhua & $\begin{array}{l}\text { North Sea, Sub-area IV, Divison VIId \& } \\
\text { Division IIIa (Skagerrak) }\end{array}$ & cod-347d* \\
\hline & & Baltic Sea, Sub-divisions 22 to 24 & cod-2224* \\
\hline \multirow[t]{2}{*}{$\mathrm{Dab}$} & Limanda limanda & North Sea, Subarea IV and Division IIIa & dab-nsea \\
\hline & & Baltic Sea, Subdivisions 22-32 & dab-2232 \\
\hline Dogfish/Spurdog & Squalus acanthias & Northeast Atlantic & spurdog \\
\hline European eel & Anguilla anguilla & Northeast Atlantic & eel-eur \\
\hline \multirow[t]{2}{*}{ Flounder } & Platichthys flesus & North Sea, Division IIIa and Subarea IV & fle-nsea \\
\hline & & Baltic Sea, Subdivisions 22-32 & fle-2232 \\
\hline \multirow[t]{2}{*}{ Herring } & Clupea harengus & $\begin{array}{l}\text { North Sea, Sub-area IV, Divisions VIId \& } \\
\text { IIIa (autumn-spawners) }\end{array}$ & her-47d3* \\
\hline & & \begin{tabular}{|lll} 
Baltic Sea, Sub-divisions 22-24 and \\
Division IIIa (spring-spawners)
\end{tabular} & her-3a22* \\
\hline Norway lobster & $\begin{array}{l}\text { Nephrops } \\
\text { norvegicus }\end{array}$ & North Sea, subarea IV & nep-IV \\
\hline \multirow[t]{3}{*}{ Plaice } & $\begin{array}{l}\text { Pleuronectes } \\
\text { platessa }\end{array}$ & North Sea, Sub-area IV & ple-nsea* \\
\hline & & \begin{tabular}{|lll}
$\begin{array}{l}\text { Baltic, Kattegat, Belt and Sounds, } \\
\text { subdivisions 21-23 }\end{array}$ & & \\
\end{tabular} & ple-2123 \\
\hline & & Baltic, subdivisions 24-32 & ple-2432 \\
\hline Sole & Solea solea & North Sea, Sub-area IV & sol-nsea* \\
\hline \multirow[t]{2}{*}{ Sprat } & Sprattus sprattus & North Sea, Sub-area IV & spr-nsea \\
\hline & & Baltic Sea, Sub-divisions 22-32 & spr-2232* \\
\hline \multirow[t]{2}{*}{ Turbot } & $\begin{array}{l}\text { Scophthalmus } \\
\text { maximus }\end{array}$ & North Sea, Subarea IV and Division IIIa & tur-nsea \\
\hline & & Baltic Sea, Subdivisions 22-32 & tur-2232 \\
\hline
\end{tabular}




\subsection{Available data}

Annual stock assessments of exploited species in the Northeast Atlantic are done by the respective working groups of the International Council for the Exploration of the Seas (ICES). However, full assessments with indication of stock size, fishing mortality and recruitment are done for only a subset of stocks, including seven of the 19 selected stocks. For the remaining 12 stocks only data on reported landings and data from research surveys were available (Froese and Sampang 2013). For these stocks, approximate parameters (proxies) were used (CFP 2013), e.g. for stock size, fishing mortality, and respective reference points. For some commercial species that are heavily fished in German waters, such as Brown shrimp (Crangon crangon) or Blue mussel (Mytilus edulis), no suitable data were found and thus these species could not be included. The only invertebrate species with some suitable data was the Norway lobster (Nephrops norvegicus).

\subsection{Selection of sub-indicators and reasonable proxies for data-limited stocks}

The Marine Strategy Framework Directive (MSFD 2008) of the European Union "establishes a framework within which Member States shall take the necessary measures to achieve or maintain good environmental status in the marine environment by the year 2020 at the latest.” A qualitative descriptor for determining good environmental status of exploited stocks is given in Annex I of the MSFD as Descriptor 3: "Populations of all commercially exploited fish and shellfish are within safe biological limits, exhibiting a population age and size distribution that is indicative of a healthy stock.” The European Commission (COM 2010) further specified three indicators for Descriptor 3:

1. The level of pressure of the fishing activity, measured either as fishing mortality $F$ relative to the one associated with the maximum sustainable yield $\left(F_{\mathrm{msy}}\right)$ or, if $F$ is unknown, the ratio between catch and biomass, with a reference point that is compatible with $F_{\text {msy. }}$

2. The spawning stock biomass (SSB) relative to the one that can produce the maximum sustainable yield ( $\left.S S B_{\mathrm{msy}}\right)$ or other suitable biomass indices.

3. The age and size distribution within the population, with the sub-indicators

i. $\quad$ Proportion of fish larger than the mean size of first sexual maturation;

ii. Mean maximum length across all species found in research vessel surveys;

iii. $95 \%$ percentile of the fish length distribution observed in research vessel surveys; 
iv. Size at first sexual maturation [relative to historic sizes], which may reflect the extent of undesirable genetic effects of exploitation.

Indicators 1 and 2 of Descriptor 3 were accepted for the purpose of this study and respective estimates or suitable proxies were obtained as described below. Looking at indicator 3 and its four sub-indicators for age and size distribution within a population, sub-indicator ii refers to different species and is thus not suitable for assessing the status of a given population. Subindicator iv refers to the reduction in mean size at maturity that is known to occur in many stocks. However, the genetic component of such change acts on a time scales of generations and thus requires sufficiently long time series of maturity data to be detectable. This subindicator was therefore not suitable for the short time series that were available for several stocks used in this study. Sub-indicator iii refers to the $95^{\text {th }}$ percentile of fish length distributions in research surveys. This indicator will decline in years with strong recruitment, thus giving a misleading negative signal in response to a positive event (Probst et al. 2013). Given these shortcomings of sub-indicators ii-iv, sub-indicator i, referring to the proportion of mature fishes, was chosen as sub-indicator for size and age and implemented as described below.

For the purpose of this study, the following sub-indicators and reference points were used and applied to the selected stocks.

1. Spawning stock size ( $S S B$; tonnes) relative to the stock size ( $\left.S S B_{\mathrm{msy}}\right)$ that can produce the maximum sustainable yield. Since estimates of $S S B_{\text {msy }}$ were not available from ICES, twice the stock size that marks the precautionary border of safe biological limits $\left(S S B_{\mathrm{pa}}\right)$ was used as a proxy for $S S B_{\mathrm{msy}}$.

2. Mortality caused by fishing $\left(F ; y^{-1}\right)$ relative to the natural mortality $\left(M\right.$; $\left.\operatorname{year}^{-1}\right)$ caused by predation, diseases, natural hazards, or old age.

3. Mean length $\left(L_{\text {mean }} ; \mathrm{cm}\right)$ in commercial catches relative to the mean length where $90 \%$ of the females have reached sexual maturity $\left(L_{\mathrm{m} 90}\right)$.

4. Abundance measured as catch-per-unit-effort (CPUE; numbers caught per hour in research surveys) in and near national marine waters relative to the mean CPUE in the time series.

These selected sub-indicators are described in more detail below. 


\subsubsection{Spawning stock size}

The stock size that can produce the maximum sustainable yield $\left(S S B_{\mathrm{msy}}\right)$ is a reference point referred to in UNCLOS (1982), UNFSA (1995), MSFD (2008), Descriptors 1 and 3 in COM (2010), and in the new Common Fisheries Policy of the European Union (CFP 2013). These laws and instruments agree that a biomass below $S S B_{\text {msy }}$ requires rebuilding of the stock. For the European Union, the CFP (2013) requires rebuilding of stocks "within a reasonable timeframe above levels that can produce the maximum sustainable yield”, with 2015 as the target year for the corresponding exploitation rates. The ratio $S S B / S S B_{\mathrm{msy}}$ is thus the legally prescribed indicator for the state of the stock with 1.0 as the lower limit reference point. As of 2013, ICES did not provide estimates of $S S B_{\text {msy }}$. However, the spawning stock biomass below which recruitment may become impaired ( $S S B_{\mathrm{pa}}$, ICES 2010) was available or could be approximated for all stocks in Table 1. Such impairment of recruitment is to be expected at stock sizes below 20\% of unexploited biomass $B_{0}$ (Beddington and Cooke 1983). Production models estimate the biomass that can produce the maximum sustainable yield at 37\% (Fox 1975 ) to $50 \%$ (Schaefer 1954) of $B_{0}$. If both $0.2 B_{0}$ and $S S B_{\text {pa }}$ mark the biomass below which reduction in recruitment may be observed, and if $S S B_{\text {msy }}$ occurs at $0.37-0.5 B_{0}$, then it follows that $2 * S S B_{\mathrm{pa}}$ is a reasonable proxy for $S S B_{\mathrm{msy}}$ until better estimates become available. The ratio $S S B /\left(2 * S S B_{\mathrm{pa}}\right)$ was thus the chosen sub-indicator for stock size.

For the twelve data-limited stocks in Table 1, no estimates of $S S B$ or $S S B_{\text {pa }}$ were available. Instead, the annual average catch of adult fish in one hour of standardized survey trawling (CPUE) was used as a proxy for SSB, after turning numbers caught into weight with a lengthweight relationship. Similarly, the average catch of juvenile fish was used as a proxy for the number of young fish entering the fishery (= recruits). The number of recruits was plotted over the biomass of adults in the year the recruits were spawned to obtain a stock-recruitment plot. A stock-recruitment function was fitted to these data to obtain the proxy biomass of adults below which recruitment declined, and a precautionary distance to this biomass was taken as a proxy for $S S B_{\mathrm{pa}}$ for data-limited stocks. Two examples of this procedure are given below.

\subsubsection{Mortality caused by fishing}

For human exploitation pressure on a stock, fishing mortality $(F)$ is the internationally recognized indicator and $F_{\text {msy }}$ is the $F$ value that lets a stock reach $S S B_{\text {msy }}$ and then results in the maximum sustainable yield (UNFSA 1995, COM 2010). The Common Fisheries Policy 
aims for reducing $F$ to $F_{\text {msy }}$ for all stocks in its jurisdiction by 2015 and "under no circumstances later than 2020" (CFP 2013). ICES provides estimates of $F_{\text {msy }}$ for the seven fully assessed stocks in Table 1 but not for the twelve data-limited stocks. The rate of natural mortality $M$ has long been used in fisheries science as a proxy for the upper limit of $F_{\text {msy }}$ (e.g. Gulland 1971, Shepherd 1981, Beddington and Cooke 1983, Clark et al. 1985, Beverton 1990, Patterson 1992, Thompson 1993, Walters and Martell 2002 \& 2004, MacCall 2009, Pikitch et al. 2012). Also, NOAA uses $M$ as proxy for $F_{\text {msy }}$ in assessments of data limited stocks (NOAA 2013). Therefore the ratio $F / M$ was chosen as sub-indicator for the level of exploitation. For consistency, the $F / M$ ratio was also applied to fully assessed stocks which had ICES estimates of $F_{\text {msy. }}$

$F$ and $M$ were available for all fully-assessed stocks in Table 1 and thus the $F / M$ ratio could be obtained directly from the data provided by ICES. For the twelve data-limited stocks, no stock-specific estimate of $M$ was available and it was derived instead from the literature or from empirical equations (Froese and Sampang 2013). Total mortality $Z$ in the data-limited stocks was estimated from the observed decline in numbers of a cohort in survey catches in three subsequent years (Cotter et al. 2009). For this purpose, a growth curve was used to transform observed lengths into age. A proxy for fishing mortality was then obtained from $F_{\text {proxy }}=Z-M$. This method provided proxy-estimates of fishing mortality for all data-limited stocks, although not for all stocks in all years, because sometimes the numbers in the surveys were too few for this type of analysis. Two examples of this procedure are given below.

\subsubsection{Mean length in commercial catches}

Size and age structure of a stock are important indicators (Cotter et al. 2009, COM 2010) of resilience against stresses such as periods of unfavorable environmental conditions which are predicted to become more frequent and more pronounced in the context of climate change (e.g. Easterling et al. 2000). Impact of fishing on size and age structure of a stock can be minimized if fishing targets the size and age of fishes where the biomass of a cohort has reached a maximum (Holt 1958, Froese et al. 2008). Also, it has been formally shown that overexploitation is less likely to occur if individuals are allowed to reproduce at least once before being caught (Myers and Mertz 1998). Several indicators have been explored by Froese and Sampang (2013) to address size and age structure of stocks. Mean length in commercial catches $L_{\text {mean }}$ relative to the length where $90 \%$ of the larger sex (here: the females) have reached maturity $L_{\mathrm{m} 90}$ was chosen for the purpose of this study. A proportion of $90 \%$ instead of the $50 \%$ typically used in stock assessment was chosen, because the corresponding 
indicator is not the length where $50 \%$ of the individuals are retained by the gear, but instead the mean length in the catch, which reflects the mean length in the exploited part of the stock. Also, the CFP (2013) explicitly refers to a "minimum conservation reference size" which has to account for size of maturity and "which replaces, where relevant, the minimum landing size”, i.e., the clear intention of the legal framework is that iteroparous species are caught after they have reached maturity. Thus, the ratio $L_{\text {mean }} / L_{\mathrm{m} 90}$ is the sub-indicator for the impact of fishing on the size and age structure of the stock. For the data-limited stocks, the mean length in commercial catches could not be derived from survey data because these use smaller mesh sizes and different fishing patterns than commercial fishers. Thus, this sub-indicator was only applied to the fully-assessed stocks.

\subsubsection{Abundance in German marine waters}

In the context of a national biodiversity indicator the abundance in national waters must also be considered. For example, North Sea cod was abundant in German marine waters in the 1970s but nearly absent after 1990. The ICES stock assessment for North Sea cod is based mainly on data from the deep-water northern subpopulation which is unlikely to repopulate the southern North Sea (ICES 2011). To capture biodiversity in national waters, abundance data from research surveys (CPUE) can be used. Unfortunately, no historic CPUE estimates with no or low or MSY exploitation levels were available as abundance reference points. As a substitute, the mean of the time series can tell us whether current abundance is above or below average. Note that because of the strong inter-annual fluctuations in CPUE, a three-year

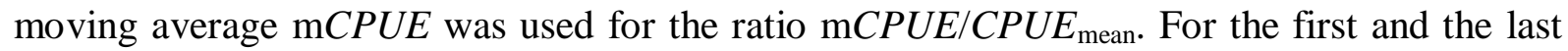
year in the time series, a two-year moving average was used to account for border effects. Two examples are given below.

\subsection{Method for summarizing sub-indicators}

There are many possible ways of summarizing sub-indicators, such as giving them equal weight and taking the arithmetic mean. However, the sub-indicator on stock size is a status indicator which addresses an overarching legal requirement (UNCLOS 1982, CFP 2013) and therefore deserves higher weight then the other three sub-indicators. This was achieved by taking the arithmetic mean of the other sub-indicators and multiplying it with the stock size sub-indicator. This was only done if the mean across the other sub-indicators was smaller than 1.0. By this procedure, the other sub-indicators were given each less weight than the stock- 
size indicator, and they could only reduce or confirm that value. For example, a too-small stock size of 0.8 could not be compensated by an $L_{\text {mean }} / L_{m 90}$ ratio of 1.3 .

For the seven fully assessed stocks, estimates for all sub-indicators were available. However, for the twelve data-limited stocks, information about mean length in commercial catches was lacking and for some of the data-limited stocks, fishing mortality was also unknown in some years. In these cases, only the available sub-indicators were used.

The calculation of the summary indicators was done for each stock in two steps as shown below.

Step 1:

$$
I_{\mathrm{FLA}}=\operatorname{mean}\left(I_{\mathrm{F}}, I_{\mathrm{L}}, I_{\mathrm{A}}\right)
$$

where $I_{F}$ is the indicator for fishing pressure, $I_{\mathrm{L}}$ is the indicator for mean length in the catch, $I_{A}$ is the indicator for abundance in national marine waters, and $I_{\mathrm{FLA}}$ is the arithmetic mean of these three sub-indicators.

Step 2: $\quad I_{\text {summary }}=I_{\mathrm{S}} *\left(I_{\mathrm{FLA}} \mid I_{\mathrm{FLA}}<1\right)$

where $I_{\text {summary }}$ is the summary indicator, which equals the stock size indicator $I_{S}$ if the mean of the other sub-indicators is $\geq 1$, or is multiplied with the mean of the other sub-indicators if that mean is $<1$.

Note that the sub-indicators for stock size, fishing mortality and mean length in catch all referred to the stock as a whole, i.e., the whole Baltic in the case of Baltic sprat (Sprattus sprattus) or the whole Northeast Atlantic in the case of European eel (Anguilla anguilla) and Dogfish (Squalus acanthias). These stock-wide estimates were used as proxies for the respective values in German marine waters, because no such estimates were available for this area.

The above procedure created annual stock-specific summary indicators for each of the selected stocks. The overall-indicator for a given year was then derived as the percentage of stocks which had a summary indicator value $I_{\text {summary }} \geq 1$. Thus, each of the 19 stocks was given equal weight.

\section{Results}

A key question is how well the proxy indicators and proxy reference points for data-limited stocks captured the true status of and pressure on these stocks. For this evaluation, scores 
resulting from the data-limited methods were compared with scores based on full assessments. Mean scores over the last 5 years for stock size and fishing pressure are presented in Table 2. For spawning stock size, most scores based on proxies deviated little from the scores derived from full assessments. All proxy scores fell on the same side of the decision framework (here: $<1.0$ ) as the biomass scores from full assessments. For fishing pressure, the scores from proxies and full assessments were also similar and on the same side of the decision framework. In summary, the proxy assessments would lead to the same qualitative evaluations of these stocks as the full assessments.

Table 2. Comparison of scores for stock size and fishing mortality, using averages over the last 5 years, between full assessments (SSB/pSSBmsy, M/F) and preliminary assessments based on survey data and life history parameters (pSSB/pSSBmsy, $2 M / Z$ ). Note that for mortality inverse ratios were used to obtain numbers $\geq 1$ in case of fulfillment of the requirements. Cases where data were insufficient to derive a proxy for fishing mortality are marked as NA. [NMS_Stocks_7.xIsx]

\begin{tabular}{|c|c|c|c|c|c|c|}
\hline Species & Stock & $\begin{array}{l}\text { NS/ } \\
\text { BS }\end{array}$ & $\begin{array}{l}S S B / \\
p S S B_{\mathrm{msy}}\end{array}$ & $\begin{array}{l}p S S B / \\
p S S B_{\text {msy }}\end{array}$ & $M / F$ & $2 M / Z$ \\
\hline \multirow[t]{2}{*}{ Cod } & cod-347d* & NS & 0.15 & 0.17 & 0.43 & 0.68 \\
\hline & cod-2224* & $\mathrm{BS}$ & 0.41 & 0.47 & 0.36 & 0.29 \\
\hline \multirow[t]{2}{*}{ Herring } & her-47d3* & NS & 0.71 & 0.46 & 3.47 & NA \\
\hline & her-3a22* & BS & 0.54 & 0.57 & 0.62 & 0.54 \\
\hline Plaice & ple-nsea* & NS & 0.87 & 0.44 & 0.43 & 0.69 \\
\hline Sole & sol-nsea* & NS & 0.44 & 0.54 & 0.28 & NA \\
\hline Sprat & spr-2232* & BS & 0.83 & 0.38 & 1.06 & NA \\
\hline
\end{tabular}

As an example of a fully assessed stock, North Sea plaice (Pleuronectes platessa) was chosen because this stock has recently recovered from overfishing (ICES 2013a), a change in status that should be recognized by the indicators. The rebuilding of spawning stock biomass of North Sea plaice is shown in Fig. 1. The biomass crossed the threshold of the proxy spawning stock biomass that can produce the maximum sustainable yield ( $\left.p S S B_{\mathrm{msy}}\right)$ in 2010 . This was a consequence of the decrease in fishing mortality shown in Fig. 2. Note, however, that fishing mortality still exceeds natural mortality and that the mean length in the commercial catches is still slightly below the length where $90 \%$ of the females have reached maturity (Fig. 2). The time series of average catch in numbers of plaice resulting from one hour of survey trawling with standardized gears (CPUE) reflects the stock abundance in the German marine waters (Fig. 3). With a recovered good overall stock status one would expect that also recent 
abundances in German marine waters were above the overall mean, with increasing or stable trend. This was indeed the case for North Sea plaice.

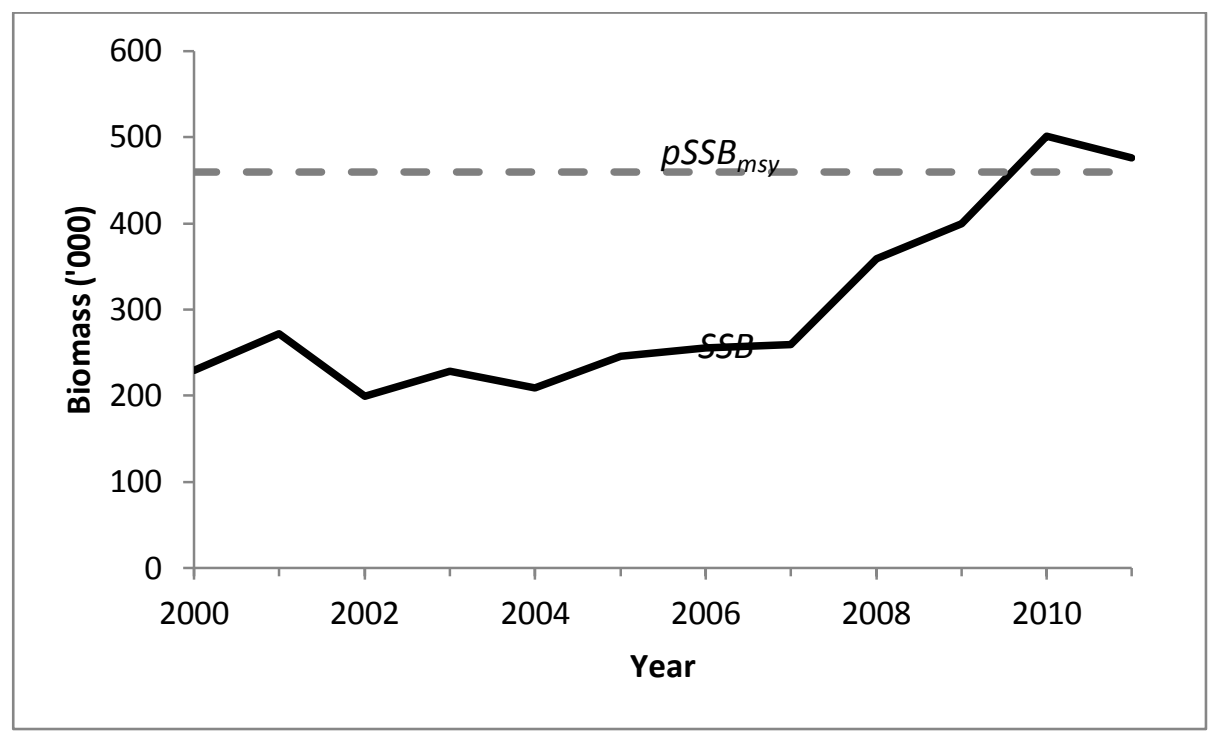

Fig. 1. Status graph: Spawning stock biomass of North Sea plaice (black curve) from 2000 to 2011, with indication of the proxy biomass that could produce the maximum sustainable yield (pSSBmsy).

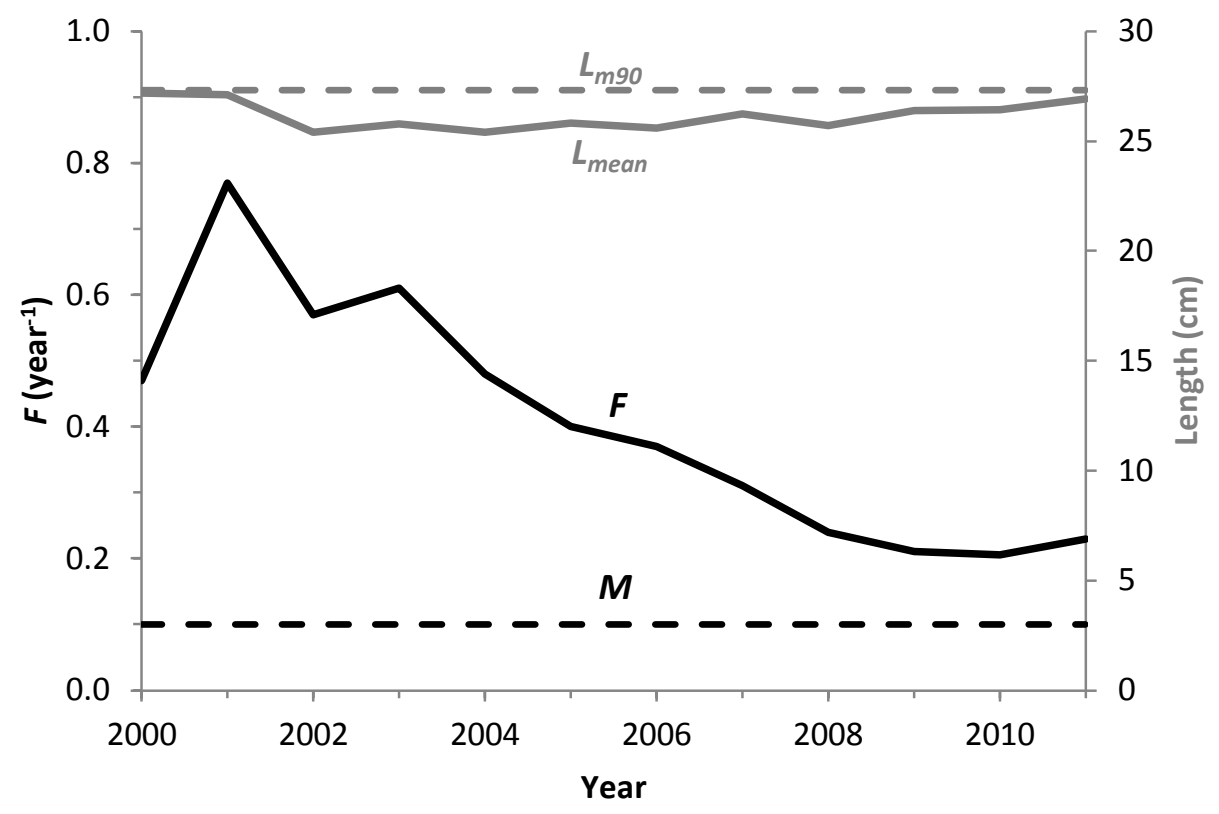

Fig. 2. Pressure graph: Fishing mortality $F$ and mean length in commercial catches Lmean, for North Sea plaice. The black dashed line indicates natural mortality $M$ as reference point for fishing mortality. The grey dashed line indicates the length $\operatorname{Lm} 90$ where $90 \%$ of the females have reached sexual maturity. 


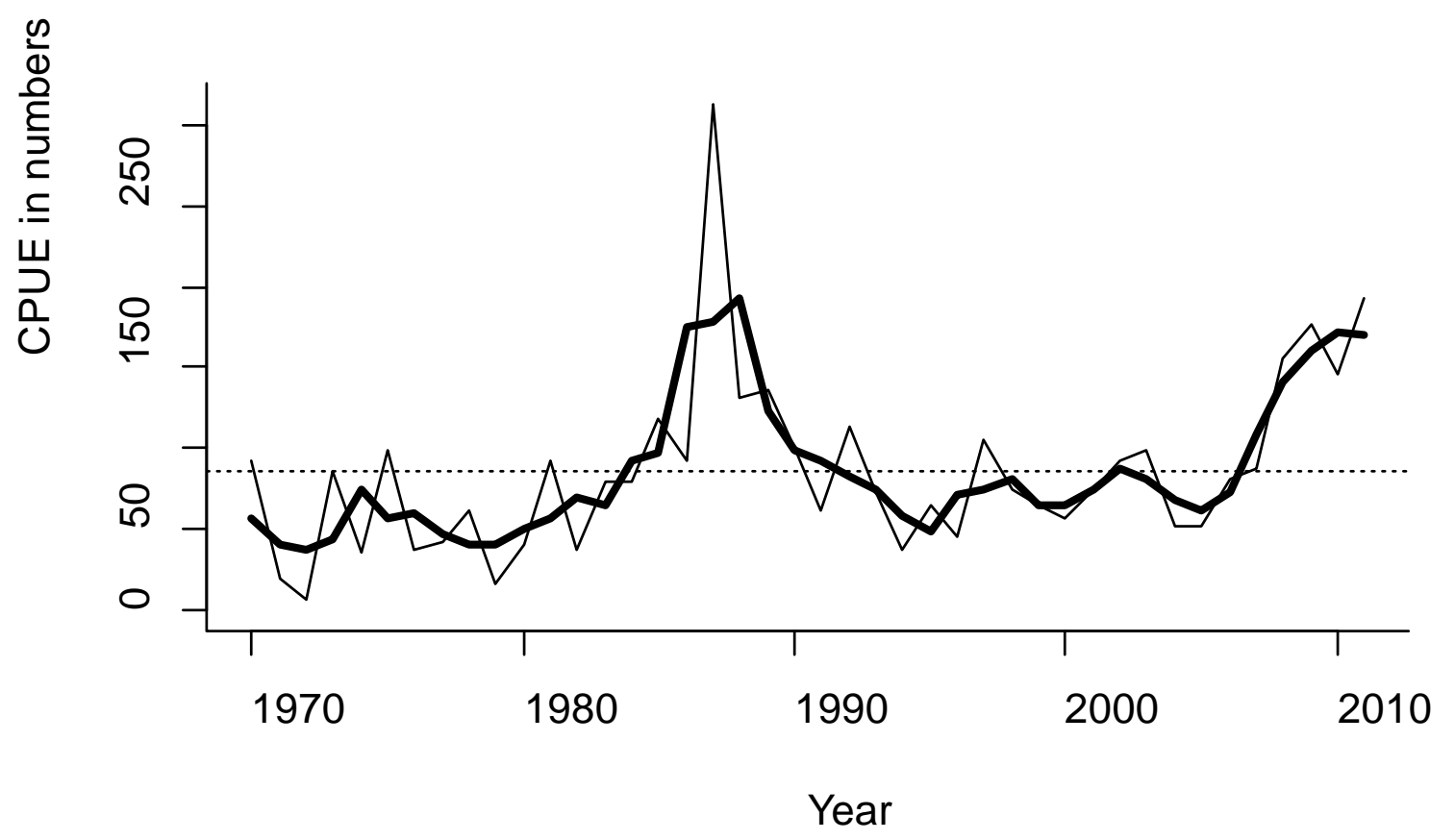

Fig. 3. Average catch in numbers of North Sea plaice resulting from one hour of trawling with standardize survey gears in the southern North Sea (ICES round fish area 6). The bold line represents a three-year moving average to reduce scatter and facilitate interpretation of trends. The dotted line indicates the mean catches over the time series. Data-limited stocks lack assessments of fishing mortality, biomass and recruitment and thus the indicators as described above cannot be applied directly. Landings data for most of these stocks are considered unreliable, mainly because they do not include discards and therefore underestimate the true catches. Available data are life history data such as growth in length, length-weight relationships, and length or age at first maturity, as derived with standard models from DATRAS SMALK data (ICES 2013b). Also, ICES provides catch per unit effort by length class and area in the DATRAS CPUE-per-length-per-area database. From combinations of these data, proxies for fishing mortality and spawning stock size were derived.

As an example of the assessment of a data-limited stock, North Sea dab (Limanda limanda) is shown in Fig. 4. Data were obtained from the DATRAS CPUE-per-length-per-area database, as annual numbers of dab per length class caught on average by one hour of standardized research trawling (Fig. 4a). The grey line in Fig. 4a indicates the number of individuals that are larger than the length at $50 \%$ female maturity $L_{\mathrm{m} 50}=15 \mathrm{~cm}$ and that are larger than the first length class that is fully retained by the gear $L_{\mathrm{v}}=17 \mathrm{~cm}$. This second condition was necessary because all fish $17 \mathrm{~cm}$ or smaller were considered to be recruits (Fig. 4b) in the sense that they have become vulnerable to the survey gear. The dashed line indicates the geometric mean of recruitment at large stock sizes (see below). Annual total mortality $Z$ 
experienced over the respective previous three years was used as a proxy for fishing mortality (Fig. 4c). No estimate of natural mortality existed for this stock, so a preliminary value of $M=$ 0.2 was assumed, which is a compromise between the $M=0.1$ often used by ICES for flatfish and the $M=1.5 K=0.32$ suggested by general life history theory (Jensen 1996), where $K$ is a parameter of the von Bertalanffy growth equation. The dashed line is the reference to fishing with $F=M$. Length of fish larger than $17 \mathrm{~cm}$ was converted to weight and summed up to show the proxy biomass of mature fish in Fig. 4d. The dashed horizontal lines are proxy reference points for spawning stock biomass. The time series suggests that spawning stock biomass has been within safe biological limits (above proxy $S S B_{\mathrm{pa}}$ ) for the past two decades, but remains well below the size that can produce the maximum sustainable yield (proxy $\left.S S B_{\mathrm{msy}}\right)$. This is consistent with the independent estimates of fishing mortality shown in Fig. 4c, which were above proxy $F_{m s y}$-levels throughout the time series and thus prevented a full recovery of the stock.

No estimates of $S S B_{\lim }$ or $S S B_{\mathrm{pa}}$ were available for North Sea dab. Therefore, spawning stock biomass and number of recruits as derived above were used to perform a stock-recruitment analysis (Fig. 5). A hockey stick was fitted by an automated procedure, where the shaft of the hockey stick represents the geometric mean number of recruits $R_{\text {inf }}$ produced by biomasses in the upper half of the range of available $S S B$ estimates, to represent average long-term recruitment at reasonably large stock sizes. The shaft is connected to the blade at the smallest biomass resulting in recruitment not less than $R_{\text {inf. }}$ The point where shaft and blade meet then marks the proxy biomass $S S B_{\text {lim }}$, below which recruitment was reduced. The same procedure was applied to the upper 95\% confidence limit of $R_{\text {inf }}$ (dotted lines) to obtain the precautionary borderline to potentially compromised recruitment proxy $S_{S} B_{\text {pa }}$. However, if this resulted in an estimate of $S S B_{\mathrm{pa}}$ that was smaller than $1.4 S S B_{\text {lim, }}$ as in our example, then $S S B_{\text {pa }}$ was set to $1.4 S S B_{\lim }$ (ICES 2010) in order to remain precautionary (Froese and Sampang 2013).

The supplementary material contains the annual results for the overall indicator, the subindicators, and the summary indicators by stock. [Supplementary Materials-1.xlsx, NMS_Stocks_7.xlsx] 

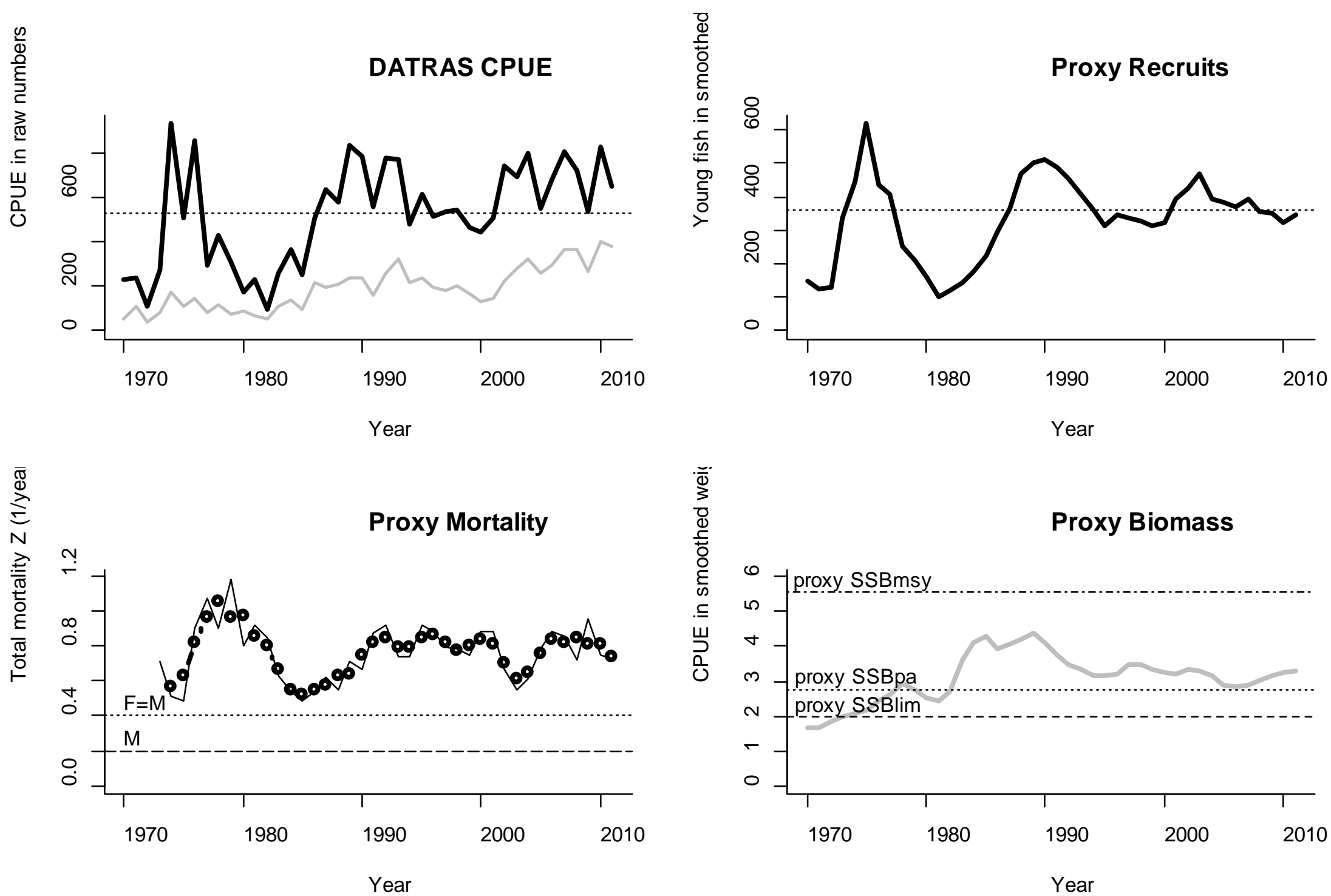

Fig. 4. Evaluation of the data-limited North Sea dab (Limanda limanda). a) The black line shows the raw data obtained from the DATRAS CPUE-perlength-per-area database, as numbers of dab caught on average per year by one hour of standardized research trawling. The gray line indicates the number of mature individuals; b) The number of "youngest fish in the survey", as proxy for recruits, with the dotted line indicating the geometric mean of recruitment at large stock sizes Rinf; c) Total mortality experienced over the respective previous three years, as a proxy for fishing mortality, with indication of natural mortality $(M)$ and total mortality if $F=M$; d) Biomass of mature fish. The dotted horizontal lines are proxy reference points for spawning stock biomass. 


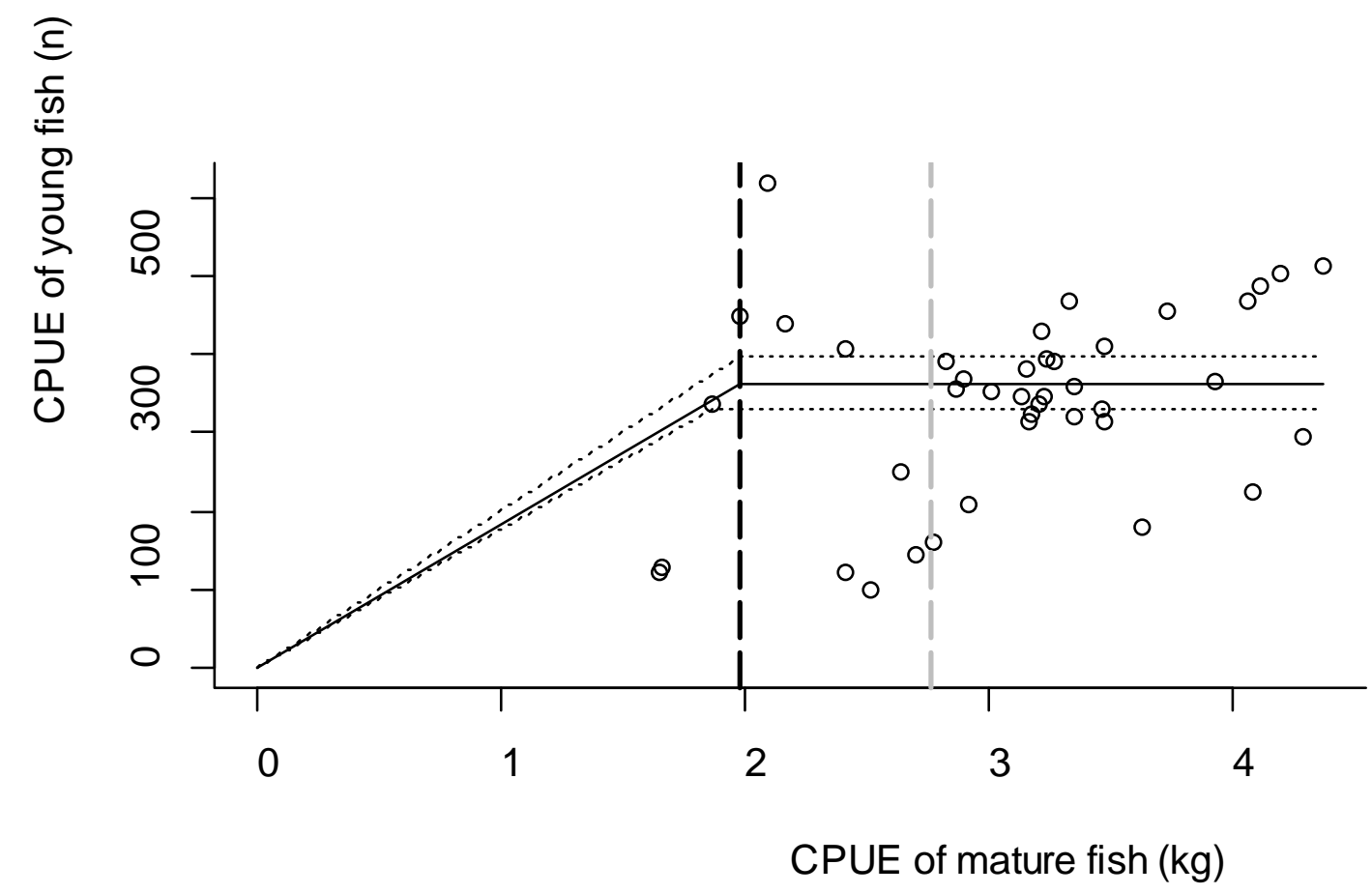

Fig. 5. A preliminary stock-recruitment relationship based on proxy biomass of mature North Sea dab and corresponding number of proxy recruits, both derived from length composition in standardized survey catches. The black vertical line indicates the proxy biomass SSBlim below which recruitment is reduced. The grey vertical line marks the precautionary borderline SSBpa to potentially compromised recruitment.

\section{Discussion}

All methods used in this study are standard fisheries methods, which were therefore only summarized with indication of key references. Some of these methods were applied beyond their traditional range, such as fitting a stock-recruitment hockey-stick model to survey data. An example application is provided that should allow interested readers to repeat this exercise. Detailed descriptions of methods and application to 19 stocks are presented as online material (Froese and Sampang 2013).

Signatories to the CBD (1992) are tasked with monitoring and evaluating biodiversity within their national jurisdiction, including national marine waters. In Europe, the Marine Strategy Framework Directive (MSFD 2008) has set the ambitious target of achieving good environmental status (GES) in EU marine waters by 2020. Towards this goal, member states have to assess and monitor their national marine waters according to a range of descriptors (COM 2010), with Descriptor 3 referring to commercially exploited fishes and invertebrates. Here, indicators and proxies that are compatible with Descriptor 3 were developed and 
applied to 7 fully assessed and 12 data-limited stocks in German marine waters. Applying the proxies also to the fully assessed stocks showed reasonable agreement with the results obtained from full assessments done by ICES with regard to stock size and fishing mortality (Table 2).

The overall-indicator for the status of 19 stocks in German marine waters between 2000 and 2011 shows that only 3 stocks (Baltic Sea dab, North Sea plaice and North Sea sprat) have passed the limit reference points for stock size, fishing mortality, age structure, and abundance in German marine waters. North Sea herring was close, but most other stocks were still far below the threshold (see Supplementary material for scores of other stocks). This disappointing result is mostly a legacy of heavy overfishing during the past two decades. But current fishing pressure is also still too high in most stocks to allow for a fast recovery of stock size, age structure and abundance (COM 2014).

The overall indicator is most strongly influenced by the sub-indicator for stock size (compare Figures in Supplementary Material for all sub-indicators). Only Baltic Sea dab, North Sea plaice and North Sea sprat had reached the legally required biomass above the level that can produce the maximum sustainable yield in 2010 and 2011. In 2000 and 2005, Baltic sprat was above that level.

While fishing pressure has been reduced in recent years in the Northeast Atlantic (Cardinale et al. 2013), there was no significant trend for the stocks occurring in German marine waters. In 2011, fishing mortality was more than twice the rate of natural mortality in 4 of 19 (21\%) stocks with available data. Fishing mortality was at or below the level of natural mortality ( $F$ $\leq M$ ) in only $58 \%$ of the stocks.

Mean length in commercial catches relative to length at $90 \%$ maturity is an indicator of the pressure on age and size structure as well as an indicator of the ability of stocks to provide large sized fishes to the fishery in sufficient numbers. In less than half (43\%) of the stocks occurring in German marine waters the mean length in commercial catches exceeded the length at maturity.

For the protection of the marine environment, abundance of native species within areas of national jurisdiction is a key concern. Since most of the examined stocks were heavily depleted in the past, average abundance presents a very low reference level. Still, cod, eel and Norway lobster had abundances in 2011 below 20\% of the reference level, suggesting a 
depleted status. Only 53\% of the stocks had better than average abundances in 2011. On the positive side, this was the only indicator with a statistically significant positive trend over the past 10 years.

This is not the first attempt to propose indicators suitable for Descriptor 3 (MSFD 2008) and to assess stocks against them. For example, ICES (2012) proposes for fishing mortality "a range within which the exploitation rate is maintained (e.g. $F_{\mathrm{msy}}+/-\mathrm{x} \%$ ) $[\ldots]$ rather than using the exact reference levels as limit or target values." In effect this proposes to use the fishing mortality associated with the maximum (!) sustainable yield $F_{\text {msy }}$ as a long-term target instead as a limit, which is incompatible with UNFSA (1995) and with the requirement of rebuilding stocks above levels that can produce MSY (CFP 2013). For spawning stock size ICES (2012) proposes the following: “To achieve sustainable levels of exploitation consistent with GES, SSB should be maintained at or above the stock specific reference level $B_{\text {MSYtrigger." }}$ This reference level is defined as follows (ICES 2012): "A level of SSB below which the stock is outside the range of values associated with $S S B_{\text {msy. }}$ An appropriate choice of $B_{\mathrm{MSY} \text { trigger }}$ requires contemporary data with fishing at $F_{\mathrm{msy}}$ to experience the normal range of fluctuations in SSB. Until this experience is gained, $B_{\mathrm{pa}}$ has, for the time being, been adopted for many stocks assessed by ICES as $B_{\mathrm{MSY} \text { trigger }}$ even though $B_{\mathrm{pa}}$ and $B_{\mathrm{MSY} \text { trigger }}$ formally correspond to different concepts.”

The MSY-concept is built around the maximum catch that a stock can provide indefinitely under the current environmental and ecological circumstances (Schaefer 1954). To be able to produce this catch, the stock must have a certain minimum size $B_{m s y}$. Thus, both $M S Y$ and $B_{m s y}$ are limit reference points. If normal fluctuations in biomass bring a stock below $B_{m s y}$, then it cannot produce MSY anymore, and fishing pressure must be reduced to respond to the legal requirement of maintaining stocks "above levels that can produce the maximum sustainable yield" (CFP 2013). Thus, the correct trigger for reducing fishing pressure is not a lower fluctuation limit of $B_{m s y}$, but instead $B_{m s y}$ itself. Such correct trigger point is implemented in harvest control rules used, e.g., by NOAA (AFSC 2008).

In other words, $B_{\text {MSYtrigger }}$ is defined by ICES as the lowest possible biomass that can be associated with $B_{\mathrm{msy}}$, which in practice is set as equal to the border of safe biological limits $B_{\text {pa. }}$. A stock at this low level is proposed as fulfilling the requirement of being above $B_{\text {msy }}$ and as indicative of a good environmental status. But clearly, fluctuations of $F$ above $F_{m s y}$ and of biomass below $B_{m s y}$ are incompatible with UNCLOS (1982), UNFSA (1995), MSFD (2008), 
COM (2010), and CFP (2013) and thus these proposals, which substantially lower the threshold for good environmental status, will not be pursued here further. As for size and age composition of a stock, ICES (2012) proposes to use the ratio of spawning biomass to total biomass, however without a proposal for a suitable reference level.

Probst et al. (2013) also propose indicators for Descriptor 3 and assess stocks against them.

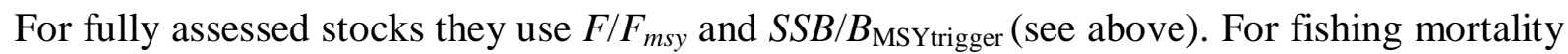
of data-limited stocks they propose to use as an annual indicator the ratio between commercial catches and average survey catches in weight $(H R)$. Fishing pressure is assumed to be compatible with GES if recent $H R$ falls below the $66^{\text {th }}$ percentile of its own time series. For stock size of data-limited stocks they used "CPUE [..] calculated as the mean weight of individuals per haul in a given survey year including all size and age classes”. Stock size is proposed to be compatible with GES if recent mean weight is above the $33^{\text {rd }}$ percentile of its own time series. For size and age structure of the stock they propose a new indicator " $L_{\max 5 \%}$ [which] is the mean total length of the observed largest $5 \%$ of the average number of individuals caught.” Size and age structure are proposed to be compatible with GES if $\mathrm{L}_{\max 5 \%}$ is above the $33^{\text {rd }}$ percentile of its own time series. We do not disagree with the indicators ( $F$, $S S B, H R, C P U E, L_{\max 5 \%}$ ) used by Probst et al. (2013), some of which are identical or similar to ours. However, except for $F_{\mathrm{msy}}$, we disagree with the chosen ad-hoc reference levels, which lack a foundation in fisheries science or ecology, and which substantially lower the threshold for achieving GES, especially for stocks that were depleted over much of their available time series. Consequently, according to Probst et al. (2013), 27 of 43 North Sea stocks (63\%) achieved GES relative to their ad-hoc reference levels, which is in stark contrast to the $16 \%$ for German marine waters found in this study, using MSY-related reference levels.

The reference points and the method of aggregation for the overall indicator may appear unnecessary strict, resulting in a strongly negative evaluation of commercial stocks in German marine waters. However, $F_{\mathrm{msy}}, B_{\mathrm{msy}}$ and size at maturity are legal reference points. Fishing pressure is set by managers and can be reduced immediately below $F_{\text {msy }}$. Most stocks will then rebuild biomass and size structure within just a few years (Froese \& Quaas 2013). Instead, according to the official estimate of the European Commission (EC 2014), 41\% of the stocks in the Northeast Atlantic and 91\% of the stocks in the Mediterranean were still fished above $F_{\text {msy }}$ in 2012, effectively preventing the recovery of these stocks. Another question is how well the status of commercial fish stocks represents the overall status of marine life. If the combined anthropogenic impacts of bottom trawling, by-catch, drilling, 
offshore construction, shipping, pollution, eutrophication and invasive species on native marine organisms are considered, then the indicator presented here may appear not as too strict but as overly optimistic.

\section{Conclusion}

The purpose of this study was to develop an overall-indicator for informing about the status of commercial stocks in national marine waters relative to a target value to be achieved within a given timeframe. The Marine Strategy Framework Directive (MSFD 2008, COM 2010) has the explicit goal of rebuilding stock sizes and age structures by 2020 in all stocks in the marine waters of EC member States. Most of the examined stocks are likely to reach the required stock sizes, abundances and age structure by 2020, given appropriate reduction in fishing pressure (Froese and Quaas 2013). Note, however, that eel and dogfish are long-lived species with low productivity and are so strongly depleted that a recovery until 2020 seems unlikely even without fishing. Similarly, North Sea cod has almost disappeared from the southern North Sea, and its rebuilding until 2020 is also unlikely. For these species, additional management measures such as reduction of by-catch and no-take areas need to be considered to aid in rebuilding of the stocks.

Obviously, a one-number overall indicator cannot do justice to all the elements that it is made of. Its purpose is to reduce and summarize highly complex information into a value that is easy to understand and to communicate and that clearly shows whether related policies have the desired effect. Here the percentage of stocks was chosen that fulfill EU-level legal requirements with regard to stock size, exploitation and age structure and that show satisfactory abundance in national marine waters. A good environmental status would be indicated by all stocks fulfilling these requirements. We hope that our example of deriving an overall indicator for the status of commercial stocks in German marine waters will be useful to the national assessment of the marine waters of other countries.

\section{Acknowledgements}

We thank Werner Ackermann, Christian Pusch and Ulrich Sukopp for conceptual input on indicators and reference points. This study was funded in part by the German Federal Ministry for the Environment, Nature Conservation, Building and Nuclear Safety on behalf of the German Federal Agency for Nature Conservation (FKZ 3512-82-0300). Rainer Froese and Arlene Sampang acknowledge support from the Lenfest Ocean Program at The Pew 
Charitable Trusts under contract ID 00002841. Nazli Demirel acknowledges support from The Scientific and Technological Research Council of Turkey (TUBITAK). This is FIN contribution number 121. Views expressed in this paper do not necessarily reflect or anticipate the views of any of the supporting agencies.

\section{References}

AFSC (2008) Amendment 24 to the Fishery Management Plan for Bering Sea/Aleutian Islands King and Tanner Crabs. Alaska Fisheries Science Center, 214 p. https://alaskafisheries.noaa.gov/analyses/amd24/KTC24finalea0508.pdf

Beddington JR, Cooke J (1983) The potential yield of previously unexploited stocks. FAO Fisheries Technical Paper 242. Food \& Agriculture Organization of the United Nations, Rome

Beverton R (1990) Small marine pelagic fish and the threat of fishing; are they endangered? J Fish Biol 37 (Suppl A):5-16

Cardinale M, Dörner H, Abella A, Andersen JL, Casey J, Döring R, Kirkegaard E, Motova A, Anderson J, Simmonds EJ, Stransky C (2013) Rebuilding EU fish stocks and fisheries, a process under way? Mar Policy 39:43-52

CBD (1992) Convention on Biological Diversity. 1760 UNTS 79; 31 ILM 818

CFP (2013) Regulation (EU) No 1380/2013 of the European Parliament and of the Council of 11 December 2013 on the Common Fisheries Policy, amending Council Regulations (EC) No 1954/2003 and (EC) No 1224/2009 and repealing Council Regulations (EC) No 2371/2002 and (EC) No 639/2004 and Council Decision 2004/585/EC. Official Journal of the European Union, L354:22-61

Clark CW, Charles AT, Beddington JR, Mangel M (1985) Optimal capacity decisions in a developing fishery. Mar Resour Econ 2:25-54

COM (2010) Commission Decision of 1 September 2010 on criteria and methodology standards on good environmental status of marine waters. Official Journal of the European Union, L232:14-24

COM (2014) Communication from the Commission to the European Parliament and the Council. Concerning a consultation on Fishing Opportunities for 2015 under the Common Fisheries Policy. COM(2014) 388 final, 17 p. 
Cotter J, Mesnil B, Witthames P, Parker-Humphreys M (2009) Notes on nine biological indicators estimable from trawl surveys with an illustrative assessment for North Sea cod. Aquat Living Resour 22:135-153

Easterling DR, Evans JL, Groisman PYa, Karl TR, Kunkel KE, Ambenje P (2000) Observed variability and trends in extreme climate events: a brief review. B Am Meteorolo Society 81(3):417-425

Fox WW (1975) Fitting the generalised stock-production model by least-squares and equilibrium approximation. Fish Bull 73: 23-26

Froese R, Quaas M (2013) Rio+20 and the reform of the Common Fisheries Policy in Europe. Mar Policy 39:53-55

Froese R, Sampang A (2013) Potential indicators and reference points for good environmental status of commercially exploited marine fishes and invertebrates in the German EEZ. http://oceanrep.geomar.de/22079/ Accessed 20 October 2013

Froese R, Stern-Pirlot A, Winker H, Gascuel D (2008) Size matters: how single-species management can contribute to ecosystem-based fisheries management. Fish Res 92:231-241

Gulland JA (1971) Preface. The fisheries resources of the ocean. Fishing News Books, West Byfleet, UK

Holt JS (1958) The evaluation of fisheries resources by the dynamic analysis of stocks, and notes on the time factors involved. ICNAF Special publication I: 77-95, Dartmouth, Canada

ICES (2010) Report of the Workshop on the Form of Advice (WKFORM), 1-3 December. 2009, Lisbon, Portugal. ICES CM 2009/ACOM:53, 15 p

ICES (2011) Report of the Workshop on the analysis of the benchmark of Cod in Subarea IV (North Sea), Division VIId (Eastern Channel) and Division IIIa (Skagerrak) (WKCOD 2011), 7-9th February 2011, Copenhagen, Denmark, ICES CM 2011/ACOM: 51, p. 94

ICES (2012) Marine Strategy Framework Directive - Descriptor 3 +. ICES Headquarters, Denmark, ICES Document CM/ACOM: 62, 169 pp 
ICES (2013a) Plaice in Subarea IV (North Sea). Advice June 2013. http://www.ices.dk/sites/pub/Publication\%20Reports/Advice/2013/2013/ple-nsea.pdf Accessed 18 November 2013.

ICES (2013b) ICES DATRAS Database.

http://datras.ices.dk/Data_products/Download/Download_Data_public.aspx. Accessed 15 April 2013

Jensen AL (1996) Beverton and Holt life history invariants result from optimal trade-off of reproduction and survival. Can J Fish Aquat Sci 53:820-822

MacCall AD (2009) Depletion-corrected average catch: a simple formula for estimating sustainable yields in data-poor situations. ICES J Mar Sci 66:2267-2271

MSFD (2008) Directive 2008/56/EC of the European Parliament and of the Council of 17 June 2008 establishing a framework for community action in the field of marine environmental policy (Marine Strategy Framework Directive). Official Journal of the European Union, L 164/19-39

Myers RA, Mertz G (1998) The limits of exploitation: a precautionary approach. Ecol Appl 8(1):5165-5169

NOAA 2013. Fishery Management Plan for Groundfish of the Bering Sea and Aleutian Islands Management Area. North Pacific Fishery Management Council, Anchorage, Alaska, 142 p. Accessible from http://www.npfmc.org/wpcontent/PDFdocuments/fmp/BSAI/BSAIfmp613.pdf.

Patterson K (1992) Fisheries for small pelagic species: an empirical approach to management targets Rev Fish Biol Fisher 2(4): 321-338

Pikitch E, Boersma PD, Boyd IL, Conover DO, Cury P, Essington T, Heppell SS, Houde ED, Mangel M, Pauly D, Plagányi É, Sainsbury K, Steneck RS (2012) Little fish, big impact: managing a crucial link in ocean food webs. Lenfest Ocean Program, Washington DC

Probst WN, Kloppmann M, Kraus G (2013) Indicator-based status assessment of commercial fish species in the North Sea according to the EU Marine Strategy Framework Directive (MSFD). ICES J Mar Sci 70:694-706 
Schaefer MB (1954) . Some aspects of the dynamics of populations important to the management of commercial marine fisheries. Bull I-ATCC 1: 25-56

Sheperd JG (1981) Cautious management of marine resources. Math Biosci 55: 179-181

Thompson GG (1993) A proposal for a threshold stock size and maximum fishing mortality rate. In: Smith SJ, Hunt JJ, Rivard D (eds) Risk evaluation and biological reference points for fisheries management. Canadian Special Publication of Fisheries and Aquatic Sciences 120: pp 303-320

UNCLOS (1982) United Nations Convention on the Law of the Sea. 1833 UNTS 3. http://www.un.org/Depts/los/convention_agreements/texts/unclos/unclos_e.pdf.

Accessed 15 April 2011

UNFSA (1995) Agreement for the implementation of the provisions of the United Nations Convention on the Law of the Sea of 10 December 1982, relating to the conservation and management of straddling fish stocks and highly migratory fish stocks. 2167 UNTS 88 .

http://www.un.org/Depts/los/convention_agreements/texts/fish_stocks_agreement/CO NF164_37.htm. Accessed 15 April 2011

Walters C, Martell SJD (2002) Stock assessment needs for sustainable fisheries management. B Mar Sci 70(2):629-638

Walters CJ, Martell SJD (2004) Fisheries ecology and management. Princeton University Press, UK 